\title{
Erratum to: The Effect of Emission Information on Housing Prices: Quasi-Experimental Evidence from the European Pollutant Release and Transfer Register
}

\author{
Kathrine von Graevenitz ${ }^{1}$. Daniel Römer ${ }^{2}$. \\ Alexander Rohlf ${ }^{3}$
}

Published online: 24 November 2016

(C) Springer Science+Business Media Dordrecht 2016

\section{Erratum to: Environ Resource Econ DOI 10.1007/s10640-016-0065-8}

The authors would like to replace Fig. 13 in the original article with the below figure. Due to a misspecification in the corresponding shape file the original figure may have given the impression that the treatment and control groups were not cleanly separated. Figure 13 clearly demonstrates the spatial distribution and the correct separation of these groups.

The online version of the original article can be found under https://doi.org/10.1007/s10640-016-0065-8.

Kathrine von Graevenitz

vongraevenitz@zew.de

Daniel Römer

roemer@zew.de

Alexander Rohlf

alexander.rohlf@gess.uni-mannheim.de

1 Centre for European Economic Research (ZEW), L7,1, 68161 Mannheim, Germany

2 Centre for European Economic Research (ZEW), Mannheim, Germany

3 University of Mannheim, Mannheim, Germany 
K. von Graevenitz et al.

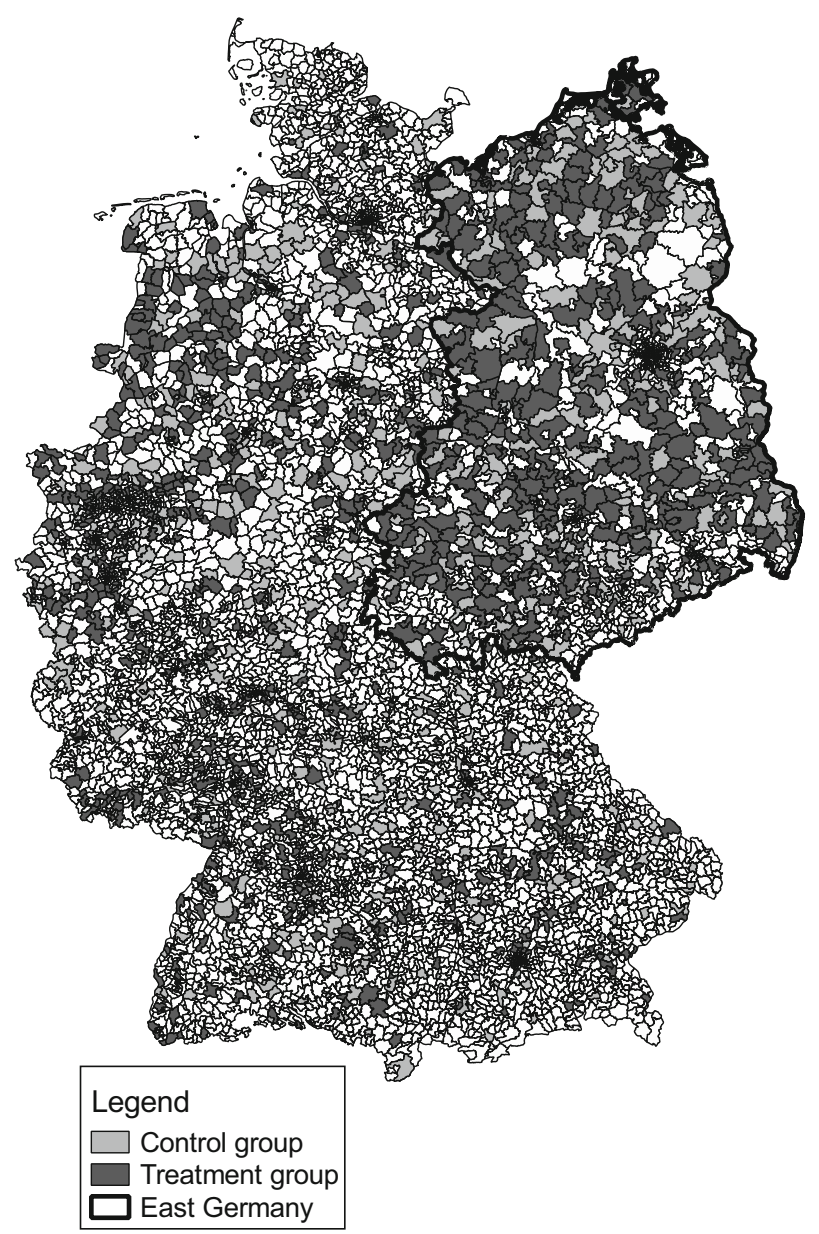

Fig. 13 Treatment and control groups with NN matching 